\title{
Downregulation of $\mathrm{Mcl}-1$ through inhibition of translation contributes to benzyl isothiocyanate- induced cell cycle arrest and apoptosis in human leukemia cells
}

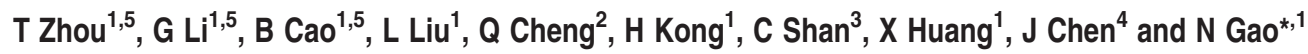

Benzyl isothiocyanate (BITC) is one of the compounds of ITCs' family that has attracted a great deal of interest because of its ability to exhibit anticancer activity. In this study, we investigated the effects of BITC on cell cycle arrest and apoptosis in human leukemia cell lines, primary leukemia cells, and nude mice Jurkat xenograft. Exposure of Jurkat cells to BITC resulted in doseand time-dependent increase in apoptosis, caspase activation, cytochrome $c$ release, nuclear apoptosis-inducing factor (AIF) accumulation, Bcl2-associated X protein (Bax) translocation, and myeloid cell leukemia-1 (Mcl-1) downregulation. Treatment with these cells also resulted in cell cycle arrest at the G2/M phase. The G2/M-arrested cells are more sensitive to undergoing Mcl-1 downregulation and apoptosis mediated by BITC. BITC downregulates Mcl-1 expression through inhibition of translation, rather than through a transcriptional, post-translational, or caspase-dependent mechanism. Dephosphorylation of eukaryotic initiation factor 4G could contribute to the inhibition of Mcl-1 translation mediated by BITC. Furthermore, ectopic expression of Mcl-1 substantially attenuates BITC-mediated lethality in these cells, whereas knockdown of Mcl-1 through small interfering RNA significantly enhances BITC-mediated lethality. Finally, administration of BITC markedly inhibited tumor growth and induced apoptosis in Jurkat xenograft model in association with the downregulation of Mcl-1. Taken together, these findings represent a novel mechanism by which agents targeting Mcl-1 potentiate BITC lethality in transformed and primary human leukemia cells and inhibitory activity of tumor growth of Jurkat xenograft model.

Cell Death and Disease (2013) 4, e515; doi:10.1038/cddis.2013.41; published online 28 February 2013

Subject Category: Cancer

Anticarcinogenic effect of cruciferous vegetables is attributed to organic isothiocyanates (ITCs) that occur naturally as thioglucoside conjugates. ${ }^{1}$ Benzyl isothiocyanate (BITC) is one of the compounds of ITCs' family that has attracted a great deal of interest because of its ability to inhibit chemically induced cancer in animal models. ${ }^{1,2}$ For instance, BITC is a potent inhibitor of mouse lung carcinogenesis and rat hepatocarcinogenesis mediated by tobacco-smoke and diethylnitrosamine..$^{3,4}$ Inhibition of benzo(a)pyrene-induced lung tumorigenesis and mammary carcinogenesis in MMTV-neu mice by BITC has also been documented. 5 .6 Preclinical data has illustrated that BITC emerges as a promising anticancer agent and it would be meaningful and challenging to develop this compound to be a novel antitumor drug. ${ }^{7}$ Currently, ITCs are in human clinical trial for treating cancer. ${ }^{8}$
Evidence supports that BITC exerts its antiproliferative effects through inducing cell cycle arrest and apoptosis. ${ }^{9}$ Several signaling pathways have been reported to be involved in BITC-triggered apoptosis, for example, p53-independent $X$-linked inhibitor of apoptosis (XIAP) downregulation, and reactive oxygen species (ROS) and $\mathrm{Bcl} 2$-associated $\mathrm{X}$ protein (Bax)/Bak-dependent pathway found in breast cancer cells, ${ }^{10,11}$ and ROS, p38- mitogen-activated protein kinases, signal transducer and activator of transcription-3, PI3K/Akt/ Foxo, and nuclear factor $-\kappa \mathrm{B}$ signaling pathways found in pancreatic cancer cells. ${ }^{12-15}$ However, little is known about other signaling pathways involved in the regulation of BITCinduced apoptosis.

Several studies have been documented that myeloid cell leukemia-1 (Mcl-1) has a critical role in cell survival, particularly in malignant hematopoietic cells. ${ }^{16} \mathrm{Mcl}-1$

\footnotetext{
${ }^{1}$ Department of Pharmacognosy, School of Pharmacy, 3rd Military Medical University, Chongqing, China; ${ }^{2} 16$ th Team of Cadet Brigade, 3rd Military Medical University, Chongqing, China; ${ }^{3} 15$ th Team of Cadet Brigade, 3rd Military Medical University, Chongqing, China and ${ }^{4}$ Department of Hematology, Southwest Hospital, 3rd Military Medical University,Chongqing, China

*Corresponding author: N Gao, Department of Pharmacognosy, School of Pharmacy, 3rd Military Medical University, 30 Gao Tan Yan Sha Ping Ba, Chongqing 400038, China. Tel: + 8623 68753736; Fax: + 8623 68753046; E-mail: gaoning59@yahoo.com.cn

${ }^{5}$ These authors contributed equally to this work.

Keywords: benzyl isothiocyanate; apoptosis; Mcl-1; translation; leukemia

Abbreviations: BITC, benzyl isothiocyanate; ITCs, isothiocyanates; ROS, reactive oxygen species; AML, acute myeloid leukemia; Mcl-1, myeloid cell leukemia-1; Bcl-2, B-cell lymphoma 2; XIAP, X-linked inhibitor of apoptosis; Bcl-xL, B-cell lymphoma-extra large; Bax, Bcl2-associated X protein; Bad, Bcl-2-associated death promoter; PARP, poly-ADP-ribose polymerase; AIF, apoptosis-inducing factor; COX, cytochrome coxidase; UV, ultraviolet; elF, eukaryotic initiation factor; siRNA, small interfering RNA; TUNEL, TdT-mediated dUTP-biotin nick-end labeling; FBS, fetal bovine serum; CHX, cycloheximide; PI, propidium iodide

Received 31.10.12; revised 23.1.13; accepted 23.1.13; Edited by A Stephanou
} 
overexpression has been shown in a variety of human leukemic cells, ${ }^{17}$ and also appears to be a key factor in the resistance of leukemia to conventional cancer therapy. ${ }^{18}$ Selective overexpression of $\mathrm{Mcl}-1$ in hematopoietic tissues of transgenic mice promotes the survival of hematopoietic cells and enhances the outgrowth of myeloid cell lines. ${ }^{19} \mathrm{Mcl}-1$ downregulation is often sufficient to promote apoptosis in leukemic cells, suggesting that $\mathrm{Mcl}-1$ can be a potential therapeutic target in the treatment of several human leukemias. ${ }^{18,20-22}$

In this study, we report for the first time that BITC potentially induces G2/M cell cycle arrest and apoptosis in human leukemia cells in association with the downregulation of $\mathrm{Mcl}-1$. These results indicate that BITC downregulates $\mathrm{Mcl}-1$ expression through inhibition of translation, rather than through a transcriptional, post-translational, or caspasedependent mechanism. Furthermore, ectopic expression of Mcl-1 substantially attenuates BITC-mediated lethality in these cells, whereas knockdown of $\mathrm{Mcl}-1$ through small interfering RNA (siRNA) significantly enhances BITC-mediated lethality. Our in vivo results indicate that BITC-mediated inhibition of growth of mouse Jurkat xenograft tumors was in association with the downregulation of Mcl-1 and induction of apoptosis. The results of this study further elucidate the mechanism of BITC as an antileukemic agent.

\section{Results}

BITC potently induces apoptosis in dose- and timedependent manners. A dose-dependent study in Jurkat cells revealed a moderate increase in apoptosis $12 \mathrm{~h}$ after exposure to $4 \mu \mathrm{M}$ BITC and very extensive apoptosis at concentrations of $6-8 \mu \mathrm{M}$ (Figure 1a). Time-course analysis of cells exposed to $8 \mu \mathrm{M}$ BITC demonstrated a significant increase in apoptosis as early as $3 \mathrm{~h}$. These events became apparent after $6 \mathrm{~h}$ of drug exposure, and reached nearmaximal levels after $12 \mathrm{~h}$ (Figure $1 \mathrm{~b}$ ).

Consistent with these findings, the same BITC concentrations and exposure intervals resulted in cleavage/activation of caspase- 9 and -3 , and degradation of poly-ADP-ribose polymerase (PARP) (Figure 1c). These events were also accompanied by the release of cytochrome $c$ and nuclear apoptosis-inducing factor (AIF) accumulation (Figure 1c). The increased level of AIF was determined in the nucleus of cells treated with BITC in a time-dependent manner (Figure 1d).

Exposure of Jurkat cells to BITC results in the downregulation of Mcl-1 and translocation of Bax. The effects of BITC on the expression of antiapoptotic B-cell lymphoma 2 (Bcl-2) family proteins were examined in Jurkat cells. A marked dose-dependent decrease of Mcl-1 expression was noted in BITC-treated cells. Exposure of cells to $8 \mu \mathrm{M}$ BITC for $3 \mathrm{~h}$ resulted in a modest decrease in levels of $\mathrm{Mcl}-1$. These events became apparent after $4 \mathrm{~h}$ and reached maximal effect after $6 \mathrm{~h}$ of drug exposure (Figure 1e). Furthermore, translocation of Bax from the cytosol to mitochondria was noted in cells treated with BITC (Figure 1e). In contrast, exposure of cells to BITC did not discernibly modify the expression of Bcl-2 family proteins, including Bcl-2, B-cell lymphoma-extra large (Bcl-xL), XIAP, or Bcl-2-associated death promoter (Bad) (Figure 1f).

G2/M-arrested cells were susceptible to BITC-mediated downregulation of $\mathrm{Mcl}-1$ and apoptosis. Exposure of cells to $2 \mu \mathrm{M}$ BITC resulted in a modest increase in percentages of cells at the G2/M phase. These events became more apparent after exposure of cells to $4 \mu \mathrm{M}$ BITC (Figure 2a). However, the population of cells at sub-G1 was observed in place of the G2/M population after exposure of cells to $8 \mu \mathrm{M}$ BITC. Therefore, BITC induces cell cycle arrest at the G2/M phase, and culminating in apoptosis in human leukemia cells.

To explore the mechanism by which BITC induces cell cycle arrest at the G2/M phase, we determined if BITC modulates the expression of $\mathrm{G} 2 / \mathrm{M}$ cell cycle regulatory molecules using western blotting. Exposure of cells to BITC resulted in a marked decrease in levels of phospho-Cdc2 in a dosedependent manner (Figure $2 \mathrm{~b}$ ). In contrast, BITC had little or no effect on the expression of cyclin A, cyclin B1, and Cdc2. These results suggest the possible involvement of Cdc2 dephosphorylation in BITC-mediated G2/M cell cycle arrest.

To determine whether G2/M-arrested cells are susceptible to the BITC-induced apoptosis, we examined the effect of BITC in cells synchronized at the G2/M phase by nocodazole treatment. Treatment of G2/M-synchronized cells with $4 \mu \mathrm{M}$ $\mathrm{BITC}$ resulted in a pronounced increase in the proportion of sub-G1 cell population and apoptosis (Figures 2c and d). Consistent with these findings, treatment of G2/M-synchronized cells with $4 \mu \mathrm{M}$ BITC also resulted in a marked increase in cleavage/activation of caspase- 9 and -3 , degradation of PARP, release of cytochrome $c$, and a pronounced decrease in levels of $\mathrm{Mcl}-1$ (Figure 2e). Such findings suggest that G2/M-arrested cells might be sensitive to undergoing downregulation of $\mathrm{Mcl}-1$ and induction of apoptosis-mediated by BITC.

BITC-induced lethality in association with Mcl-1 downregulation in multiple leukemia cell lines and primary human leukemia cells. To determine whether BITCmediated lethality observed in Jurkat cells also occur in other leukemia cell lines, parallel studies were carried out in U937 and HL-60 cells. Exposure of Jurkat and U937 cells to $8 \mu \mathrm{M}$ BITC for $12 \mathrm{~h}$ resulted in a pronounced increase in apoptosis (Figure 3a). Also, these cells exhibited comparable degrees of caspase- 9 and -3 activation, PARP degradation, cytochrome $c$ release, and $\mathrm{Mcl}-1$ downregulation (Figures $3 \mathrm{~b}$ and c). However, HL-60 cells are more refractory to apoptosis induction by BITC than those cells, and exhibited less degrees of caspase- 9 and -3 activation, cytochrome $c$ release, and $\mathrm{Mcl}-1$ downregulation.

To determine whether BITC could also trigger apoptosis in primary human leukemia cells, parallel experiments were carried out in primary leukemia blasts from eight acute myeloid leukemia $(A M L)$ patients. Exposure of these $A M L$ blasts to $8 \mu \mathrm{M} \mathrm{BITC}$ for $24 \mathrm{~h}$ resulted in a marked increase in apoptosis (Figure 3d). Consistent with these findings, treatment of leukemia blasts from two AML patients with BITC also resulted in cleavage/activation of caspase- 9 and -3 , degradation of PARP, release of cytochrome $c$, and downregulation of $\mathrm{Mcl}-1$ 

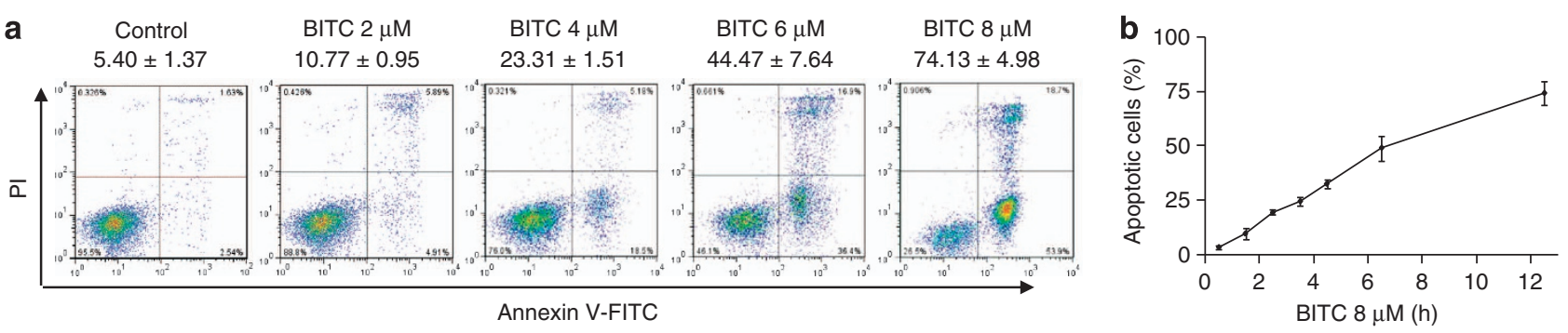

C

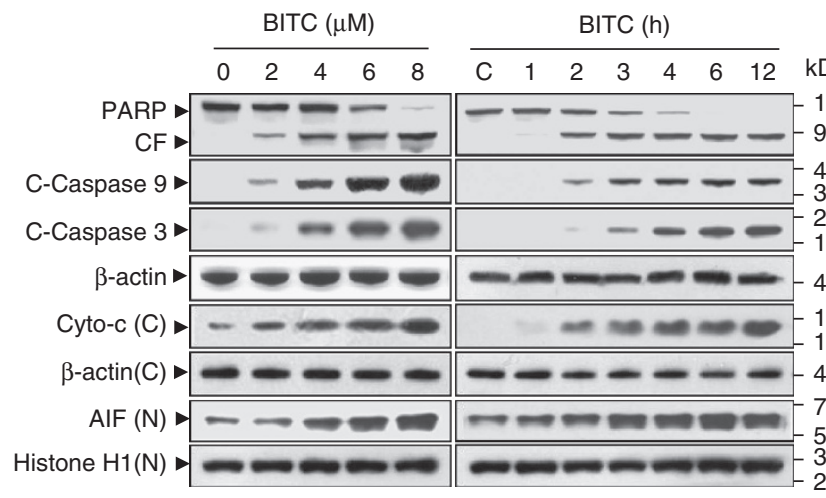

d

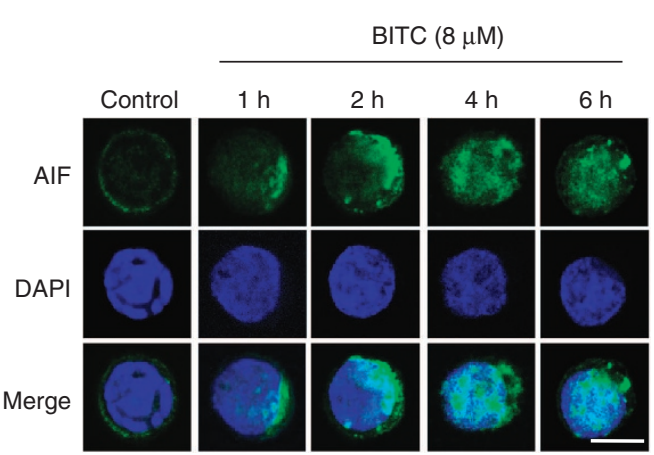

e

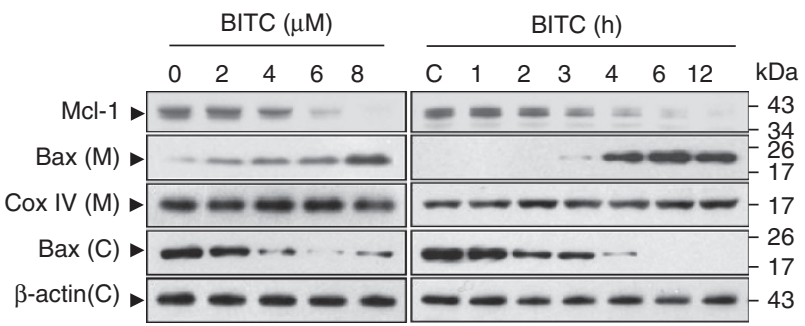

f

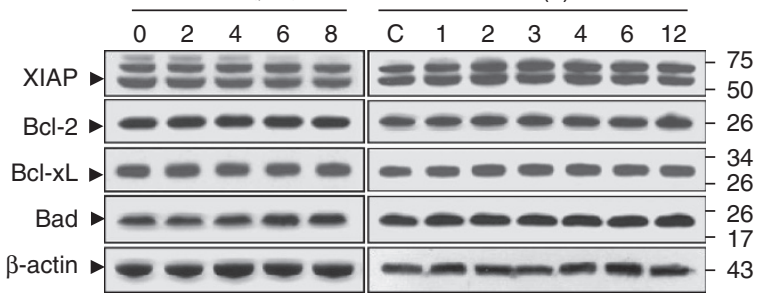

Figure 1 Treatment with BITC results in Mcl-1 downregulation, translocation of Bax, nuclear AIF accumulation, release of cytochrome $c$, caspase activation, and apoptosis in dose- and in time-dependent manners in Jurkat cells. (a) Jurkat cells were treated with $0,2,4,6$, and $8 \mu \mathrm{M} \mathrm{BITC}$ for $12 \mathrm{~h}$. (b) The cells were treated with $8 \mu \mathrm{M}$ BITC for 0,1 , 2, 3, 4, 6, and $12 \mathrm{~h}$. In (a) and (b), cells were stained with Annexin V/PI, and the percentage of apoptotic cells was determined using flow cytometry. (c) After treatment with BITC, total cellular extracts, nuclear extracts, and cytosolic fractions were prepared and subjected to western blot analysis using antibodies against PARP, cleaved-caspase (C-Caspase)-9, cleaved-caspase-3, cytochrome c, and AIF. (d) AIF immunostaining (green) of Jurkat cells treated with $8 \mu$ M BITC for 0, 1, 2, 4, and 6 h, with 4',6-diamidino-2phenylindole (DAPI) staining of the nucleus (blue). Scale bar represents $10 \mu \mathrm{m}$. (e and f) Western blot was used to analyze the expression of Mcl-1, Bax, XIAP, Bcl-2, Bcl-xL, and Bad. Blots were subsequently stripped and reprobed with antibody against $\beta$-actin, COX IV (mitochondrial fraction), and histone $\mathrm{H} 1$ (nuclear extracts) to ensure equivalent loading. Each lane was loaded with $30 \mu \mathrm{g}$ of protein. Two additional studies yielded equivalent results. C, cytosolic fractions; M, mitochondrial fractions; N, nuclear extracts

(Figure 3e). These findings indicate that BITC induces apoptosis in association with Mcl-1 downregulation in both human leukemia cell lines and primary leukemia blasts. In contrast, BITC exerted little toxicity toward normal human peripheral blood mononuclear cells (Figure $3 \mathrm{f}$ ). No change in expression of Mcl-1 was noted in BITC-treated cells.

Downregulation of Mcl-1 by BITC proceeds through inhibition of translation. To elucidate the mechanism underlying Mcl-1 downregulation by BITC, Mcl-1 mRNA expression in BITC-treated cells was quantified using realtime RT-PCR. Notably, treatment of cells with $8 \mu \mathrm{M}$ BITC for different time intervals did not alter the expression of Mcl- 1 at mRNA levels (Figure 4a). Furthermore, treatment with BITC had no significant effect on luciferase driven by an Mcl-1 promoter (Figure 4b). Such findings suggest that BITC induces $\mathrm{Mcl}-1$ downregulation through transcriptionindependent mechanism.
To determine whether the downregulation of $\mathrm{Mcl}-1$ mediated by BITC occurs through post-translational mechanism, Jurkat cells were exposed to $8 \mu \mathrm{M}$ BITC for various intervals in the presence or absence of the proteasome inhibitor MG132 $(10 \mu \mathrm{M})$. Treatment with MG132 alone did not affect the decline of Mcl-1 levels. Exposure of cells to BITC resulted in the downregulation of Mcl-1 in a time-dependent manner (Figure 4c). However, pretreatment of cells with MG132 did not block the downregulation of Mcl-1 mediated by BITC. To validate the action of MG132, we used ubiquitin as a control protein, with levels clearly increased upon proteasomal inhibition (Figure 4d). These findings suggest that downregulation of Mcl-1 mediated by BITC does not occur through post-translational mechanism.

We also determined the effect of caspase inhibition on $\mathrm{Mcl}-1$ stability. Although pretreatment with caspase inhibitor Z-VAD blocked BITC-induced apoptosis and caspase-9 and -3 activation, it blocked the downregulation of Mcl-1 
a
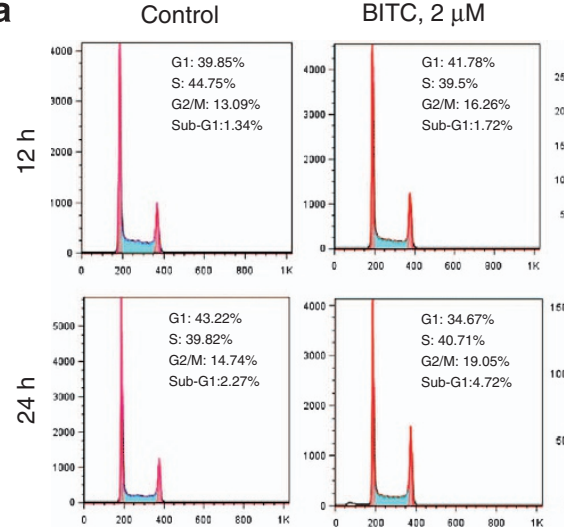

BITC, $4 \mu \mathrm{M}$
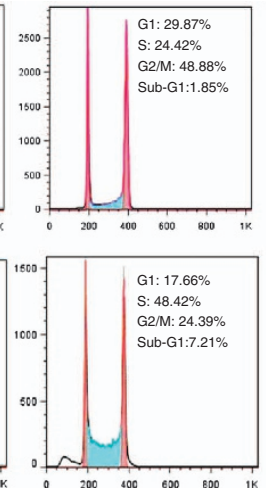

d
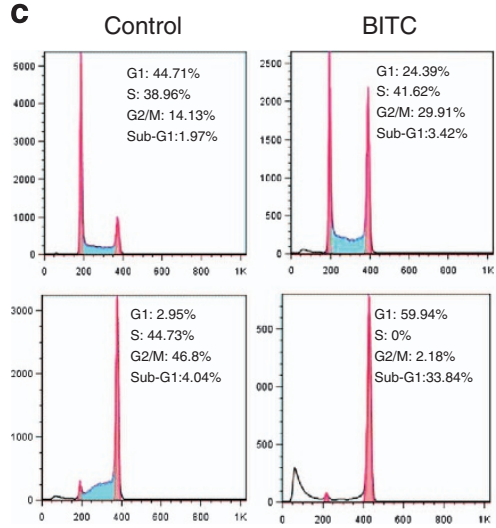

Noc

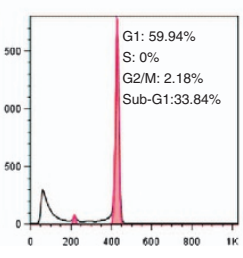

BITC+Noc

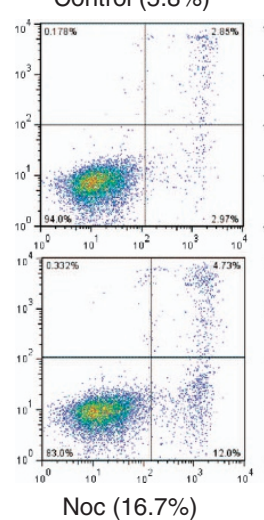

BITC, $8 \mu \mathrm{M}$
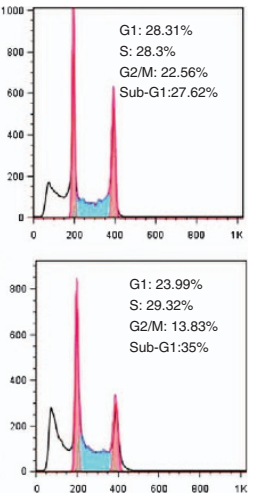

b

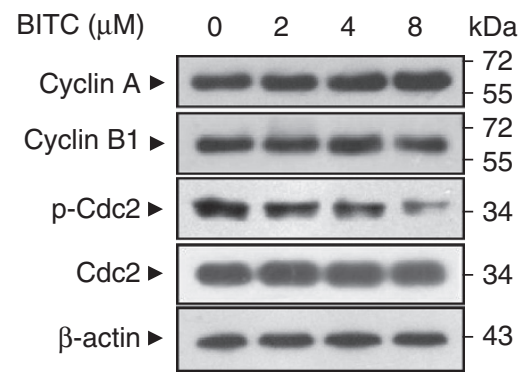

e

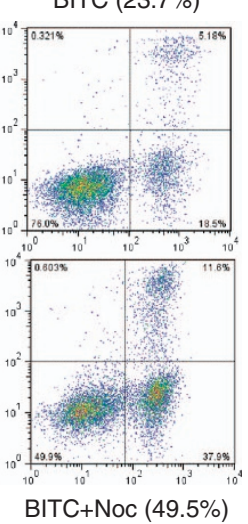

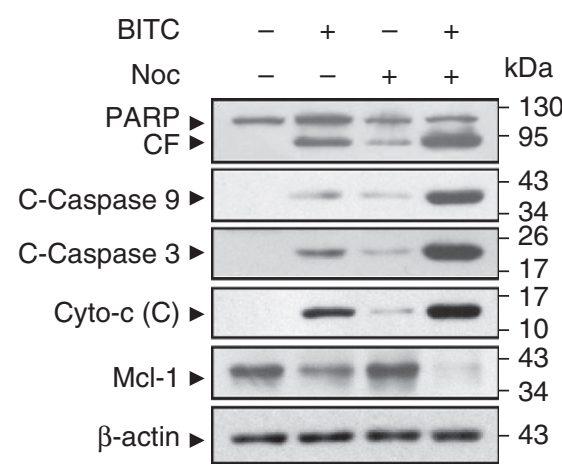

Figure 2 Effect of BITC on the cell cycle progression in Jurkat cells. (a) Jurkat cells treated with BITC at indicated concentrations for 12 and $24 \mathrm{~h}$ were stained with cell cycle staining solution as described in Materials and Methods, and analyzed using a flow cytometer. Cell cycle distribution (\%) was measured using the FlowJo. (b) Jurkat cells treated with BITC at indicated concentrations for $12 \mathrm{~h}$, whole-cell lysates were obtained and subjected to western blot analysis using antibodies against cyclin A, cyclin B1, Cdc2, phospho-Cdc2 (p-Cdc2), and $\beta$-actin. (c) Jurkat cells were pretreated with $100 \mathrm{ng} / \mathrm{ml}$ nocodazole for $12 \mathrm{~h}$, followed by treatment with or without $4 \mu \mathrm{M}$ BITC for $12 \mathrm{~h}$. After treatment, cells were stained with cell cycle staining solution as described in Materials and Methods, and analyzed using a flow cytometer. Cell cycle distribution (\%) was measured using the FlowJo. (d) After the same treatment, cells were stained with Annexin V/PI, and the percentage of apoptotic cells was determined using flow cytometry. (e) Alternatively, the whole-cell lysates and cytosolic fractions were obtained and subjected to western blot analysis using antibodies against PARP, cleaved-caspase (C-Caspase)-9, cleaved-caspase-3, Mcl-1, cytochrome $c$, and $\beta$-actin. Each lane was loaded with $30 \mu \mathrm{g}$ of protein. Two additional studies yielded equivalent results

partly (Figures $4 \mathrm{e}$ and f). These findings demonstrate that Mcl1 downregulation induced by BITC is affected by caspase inhibition, albeit not completely.

Lastly, we investigated the effect of protein synthesis inhibitor cycloheximide (CHX) on the downregulation of $\mathrm{Mcl}-1$ mediated by BITC. Treatment with $\mathrm{CHX}$ alone reduced $\mathrm{Mcl}-1$ protein level, and combined treatment with $\mathrm{CHX}$ and BITC decreased Mcl-1 protein level at a enhanced rate. Moreover, $\mathrm{CHX}$ prevented the accumulation ubiquitin proteins (Figure 5a). Such findings demonstrate that BITC-induced Mcl-1 downregulation could be caused by the inhibition of protein synthesis. To further confirm these possibilities, we pulse-labeled cells with $\left[{ }^{35}\right.$ S $]$ methionine and chased with or without BITC treatment. Newly synthesized $\mathrm{Mcl}-1$ was analyzed by immunoprecipitation. Mcl- 1 protein in cells prelabeled with $\left[{ }^{35} \mathrm{~S}\right]$ methionine was decreased at a similar rate following treatment without or with BITC, even though the total amount of Mcl-1 protein was dramatically decreased after BITC treatment, whereas no major changes were observed in protein synthesis of the housekeeping genes $h s p 90$ and $\beta$-actin (Figure $5 \mathrm{~b}$ ). These findings indicate that BITC induces $\mathrm{Mcl}-1$ downregulation through inhibition of translation.

To identify changes in the translational efficiency of individual mRNAs during BITC-induced apoptosis, we isolated ribosomal fractions from extracts of cells treated with or without BITC. By ultracentrifugation in sucrose gradients, we separated the $40 S$ and 605 complexes, which correspond to untranslated mRNAs (U in Figure $5 \mathrm{c}$ ) and the polysomal fractions that contains mRNAs that are being efficiently translated into proteins ( $P$ in Figure $5 \mathrm{c}$ ). Exposure of cells to BITC resulted in a considerable decrease in the amount of polysomes and a corresponding increase in the abundance of the $40 \mathrm{~S}$ and $60 \mathrm{~S}$ complexes (Figure $5 \mathrm{c}$ ), suggesting that inhibition of protein translation occurs during BITC-induced apoptosis. We then quantified by real-time RT-PCR, the transcripts corresponding to actin and $\mathrm{Mcl}-1$ mRNAs in both $U$ and $P$ fractions and plotted the $P / U$ ratio (Figure $5 d$ ). Actin mRNA is actively translated in untreated cells, as indicated by a $P / U$ ratio 2 , whereas a ratio of 1.5 was observed for 
a
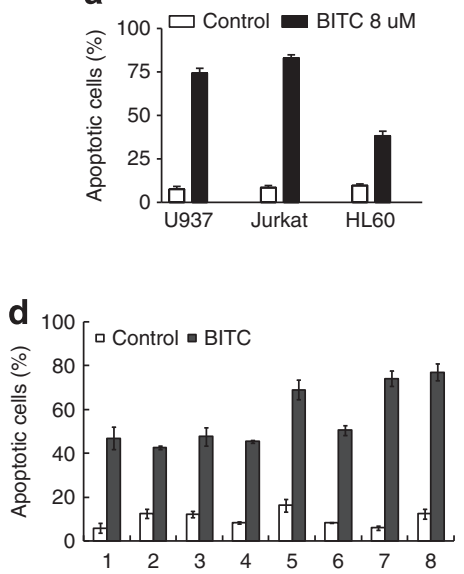

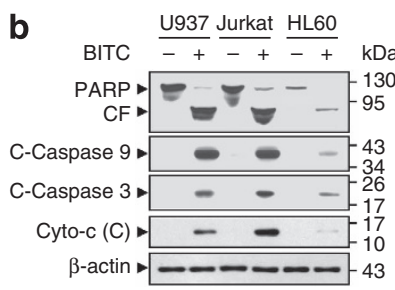

\section{C}

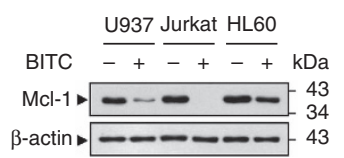

e

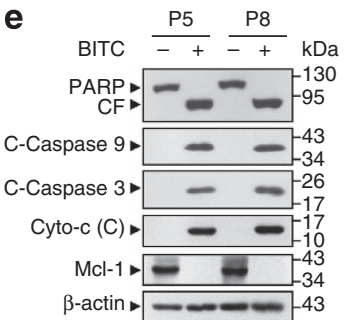

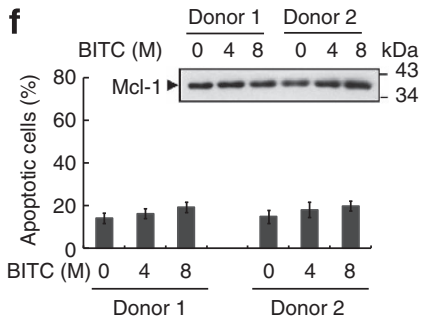

Figure 3 Exposure to BITC results in a marked increase in apoptosis in association with Mcl-1 downregulation in multiple leukemia cell lines and primary human leukemia cells but not normal human peripheral blood mononuclear cells. (a) U937, Jurkat, and HL-60 cells were treated with or without $8 \mu \mathrm{M} \mathrm{BITC}$ for $12 \mathrm{~h}$. After treatment, cells were stained with Annexin V/PI, and apoptosis was determined using flow cytometry as described in the Materials and Methods section. The values obtained from Annexin V/PI assays represent the mean \pm S.D. for three separate experiments. ( $\mathbf{b}$ and $\mathbf{c}$ ) Whole-cell lysates and cytosolic fractions $(C)$ were obtained and subjected to western blot analysis using antibodies against PARP, cleaved-caspase (C-Caspase)-9, cleaved-caspase-3, cytochrome $c$, Mcl-1, and $\beta$-actin. (d) Primary leukemia blasts were isolated from the peripheral blood of eight patients with AML as described in the Materials and Methods section. After exposure to $8 \mu \mathrm{M}$ BITC for $24 \mathrm{~h}$, the extent of apoptosis was determined using flow cytometry. The values obtained from Annexin V/PI assays represent the mean \pm S.D. for three separate experiments. (e) Whole-cell lysates and cytosolic fractions $(C)$ in blasts from two AML patients were obtained and subjected to western blot analysis using antibodies against PARP, cleaved-caspase-9, cleavedcaspase-3, Mcl-1, cytochrome $c$, and $\beta$-actin. (f) Normal human peripheral blood mononuclear cells, exposed to designated concentration of BITC for $24 \mathrm{~h}$, after which the extent of apoptosis was determined using flow cytometry. Alternatively, whole-cell lysates were obtained and subjected to western blot analysis to monitor expression of Mcl-1. Each lane was loaded with $30 \mu \mathrm{g}$ of protein. Two additional studies yielded equivalent results

Mcl-1 mRNA. This implies that the two mRNAs are being translated, although Mcl-1 mRNAs are present in lower amounts than actin. After BITC treatment, we observed a sharp decrease of polysome-associated Mcl-1 mRNAs $(P / U<1)$ and a slight decrease in the levels of the capdependent actin mRNAs. Our results indicate that capdependent translation might be preferentially impaired.

To elucidate further mechanism by which BITC might inhibit $\mathrm{Mcl}-1$ translation, we examined the status of the initiation complex eukaryotic initiation factor (elF)4E and elF4G. Treatment with BITC for $2 \mathrm{~h}$ resulted in a striking suppression of elF4G phosphorylation. These events became apparent after $3 \mathrm{~h}$ of drug exposure. Treatment with BITC also caused a decrease in the expression of total elF4G at late time intervals (Figure 5e). However, treating with BITC resulted in a modest increase in levels of phospho-elF4E after $2 \mathrm{~h}$ of drug exposure, and then returned to the initial level after $12 \mathrm{~h}$ of treatment. Furthermore, phosphorylation of the elF4E-binding protein 1 declined after BITC treatment. These observations suggest that BITC-mediated inhibition of elF4G phosphorylation may be involved in the inhibition of $\mathrm{Mcl}-1$ translation.

Enforced expression of Mcl-1 substantially attenuates BITC-mediated apoptosis. To determine whether downregulation of $\mathrm{Mcl}-1$ has a functional role in BITC-induced apoptosis, Jurkat cells stably overexpressing $\mathrm{Mcl}-1$ were employed. Two selected populations of cells, Mcl-1(C8) and $\mathrm{Mcl}-1$ (C12), displayed two- to threefold increases in Mcl-1 protein levels compared with empty vector control cells (Figure 6a). Significantly, enforced expression of Mcl-1 attenuated BITC-mediated apoptosis, activation of caspase-9 and -3, degradation of PARP, and release of cytochrome $c$ (Figures $6 \mathrm{a}$ and $\mathrm{b}$ ). Although a slight reduction in the expression of ectopic $\mathrm{Mcl}-1$ was observed in infectants exposed to $8 \mu \mathrm{M} \mathrm{BITC}$, as one would expect of an inhibitor of translation, the Mcl-1 levels in BITC-treated infectant cells were higher than that in untreated control cells (Figure 6c). These data indicate that downregulation of $\mathrm{Mcl}-1$ has a critical role in BITC-induced apoptosis in leukemia cells.

Knockdown of $\mathrm{Mcl}-1$ by RNA interference enhances BITC-mediated apoptosis. To further confirm the functional role of $\mathrm{Mcl}-1$ in BITC-mediated lethality in leukemia cells, Jurkat cells stably expressing $\mathrm{Mcl}-1$ siRNA were employed. The knockdown of Mcl-1 in Jurkat cells led to a nearly two- to threefold increase in BITC-mediated apoptosis compared with control cells (Figure 6d). BITC was also considerably more effective in triggering the activation of caspase-9 and -3 , degradation of PARP, and release of cytochrome $c$ (Figure 6e). Furthermore, infection of cells with Mcl-1 siRNA reduced levels of total $\mathrm{Mcl}-1$ compared with control cells. Exposure of these cells to BITC resulted in a significant reduction of $\mathrm{Mcl}-1$ expression compared with control cells (Figure 6f). Taken together, these findings indicate that $\mathrm{Mcl}-1$ downregulation has a significant functional role in BITC-mediated lethality.

BITC exhibits antitumor activity in xenografts of leukemia Jurkat cells by induction of apoptosis and downregulation of $\mathbf{M c l}-\mathbf{1}$. The in vivo antitumor activity of BITC on leukemia Jurkat cells was further evaluated in a nude mouse xenograt model. Treatment with BITC resulted 

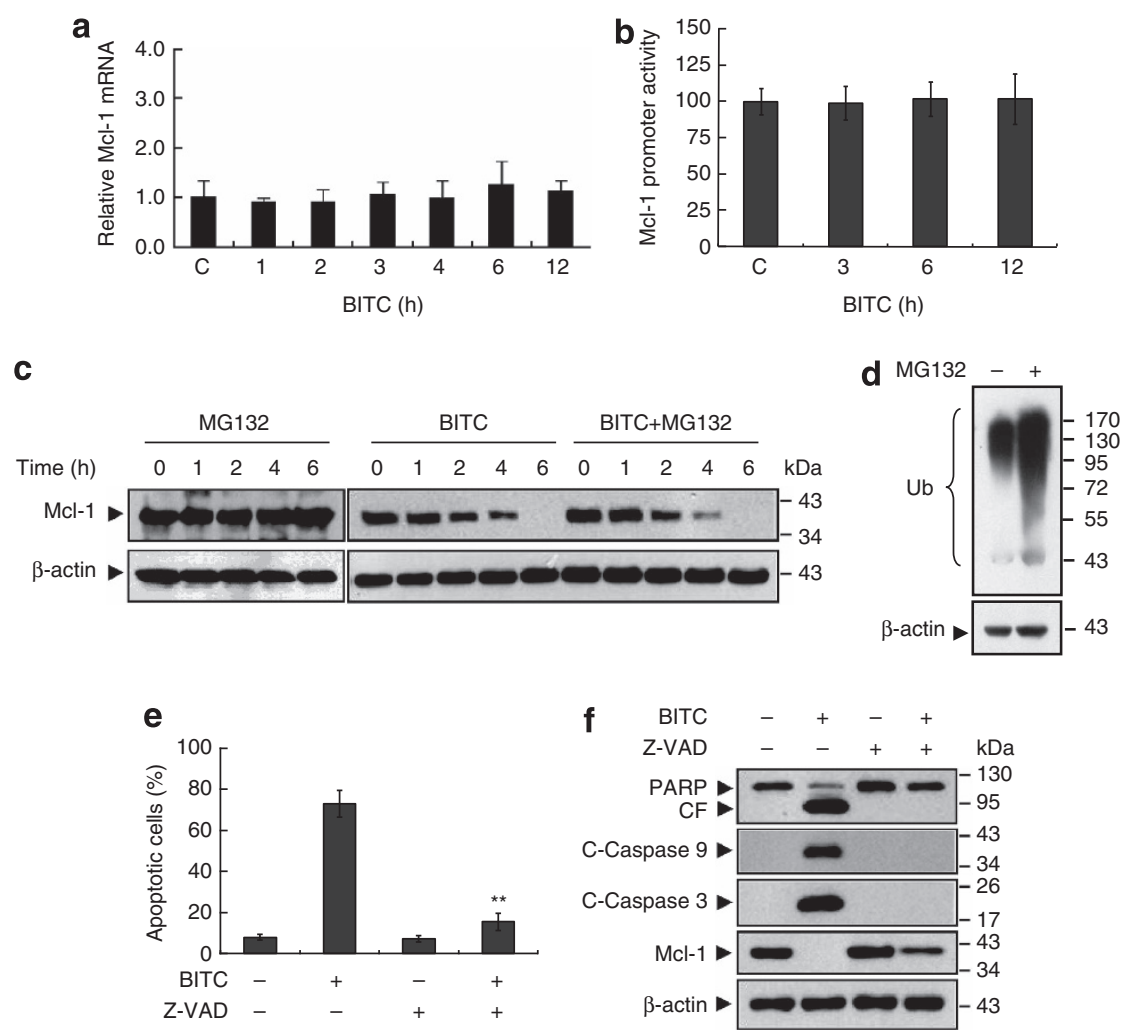

Figure 4 BITC induces Mcl-1 downregulation through the independent transcriptional and post-translational mechanisms. (a) Jurkat cells were treated with $8 \mu \mathrm{M}$ BITC at the designated intervals, after which total RNA were isolated and Mcl-1 mRNA were quantified using real-time reverse transcription-polymerase chain reaction (RT-PCR) as described in the Materials and Methods section. (b) Jurkat cells were cotransfected with ( - 203/ + 10-Mcl-1-pGL2) or pGL2-Basic and pRL-TK-luc plasmids. Cells were incubated for $12 \mathrm{~h}$ and then treated with BITC for $0,3,6$, and $12 \mathrm{~h}$, after which activity of firefly and Renilla luciferase was monitored as described in the Materials and Methods section. Values for firefly luciferase activity were normalized to those obtained for Renilla luciferase activity, after which values obtained for ( $-203 /+10-M c l-1-p G L 2)$ transfected cells were divided by the corresponding values obtained for pGL2-Basic-transfected cells. The graph shown represents the mean \pm S.D. in four separate experiments. (c) Jurkat cells were treated with MG132 $(10 \mu \mathrm{M})$, BITC $(8 \mu \mathrm{M})$, or cotreated with MG132 and BITC for different exposure intervals as indicated. Total cellular extracts were prepared and subjected to western blot assay using antibodies against Mcl-1 and $\beta$-actin. (d) Jurkat cells were treated with or without MG132 (10 $\mu \mathrm{M}$ ) for $4 \mathrm{~h}$, and whole-cell lysates were obtained and subjected to western blot analysis using antibodies against ubiquitin (Ub) and $\beta$-actin. (e) Jurkat cells were pretreated with Z-VAD $(10 \mu \mathrm{M})$ for $2 \mathrm{~h}$, followed by treatment with $8 \mu \mathrm{M}$ BITC for $12 \mathrm{~h}$. After treatment, apoptosis was determined using flow cytometry. The values obtained from Annexin V/PI assays represent the mean \pm S.D. for three separate experiments. ${ }^{*}$ Values for cells treated with BITC and Z-VAD were significantly reduced compared with values obtained for BITC alone by Student's $t$-test; $P<0.01$. (f) Whole-cell lysates were obtained and subjected to western blot analysis using antibodies against PARP, cleaved-caspase (C-Caspase)9, cleaved-caspase-3, Mcl-1, and $\beta$-actin

in a dramatic suppression of tumor growth 10 days following drug exposure $(P<0.05$ versus vehicle control). These events became more apparent 15 and 20 days after drug exposure $(P<0.01$ between BITC treatment and vehicle control) (Figure 7a). In contrast, no significant change in body weight was noted comparing vehicle control and BITC regimen (Figure $7 \mathrm{~b}$ ), indicating that no severe toxicity was observed.

We further determined apoptosis in tumor tissue of leukemia xenograft using TdT-mediated dUTP-biotin nickend labeling (TUNEL) assay. TUNEL-positive apoptotic cells of tumor sections significantly increased in BITC-treated Jurkat xenograft mice compared with the control group. Exposure of mice to BITC also caused a rapid increase in immunoreactivity for cleaved-caspase-3 in tumor sections, indicative of apoptosis. Furthermore, Mcl-1 expression in tumor sections of Jurkat xenograft mice decreased upon BITC treatment (Figure 7c). Such findings suggest that BITCmediated antileukemic activity in vivo is associated with the downregulation of Mcl-1.

\section{Discussion}

The results of this study indicate that treatment with BITC results in G2/M cell cycle arrest and apoptosis in human leukemia cells. Notably, this study demonstrates for the first time that downregulation of $\mathrm{Mcl}-1$ through inhibition of translation has an important role in BITC-mediated lethality.

Extensive evidence is accumulating that $\mathrm{Mcl}-1$ expression has a critical role in the survival of transformed cells, ${ }^{23}$ particularly those of hematopoietic origin. ${ }^{21}$ The development of anticancer agents that diminish $\mathrm{Mcl}-1$ protein levels has been the focus of intense interest. Indeed, a number of studies have documented $\mathrm{Mcl}-1$ downregulation during apoptosis by a variety of agents, including ultraviolet (UV), ${ }^{24}$ kinase inhibitor BAY43-9006, ${ }^{25}$ growth factor withdrawal, ${ }^{26}$ among others. Evidence revealed that $\mathrm{Mcl}-1$ protein levels are regulated through several different mechanisms, including those operating at the transcriptional, translational, and posttranslational levels. These results reveal that BITC induces a 

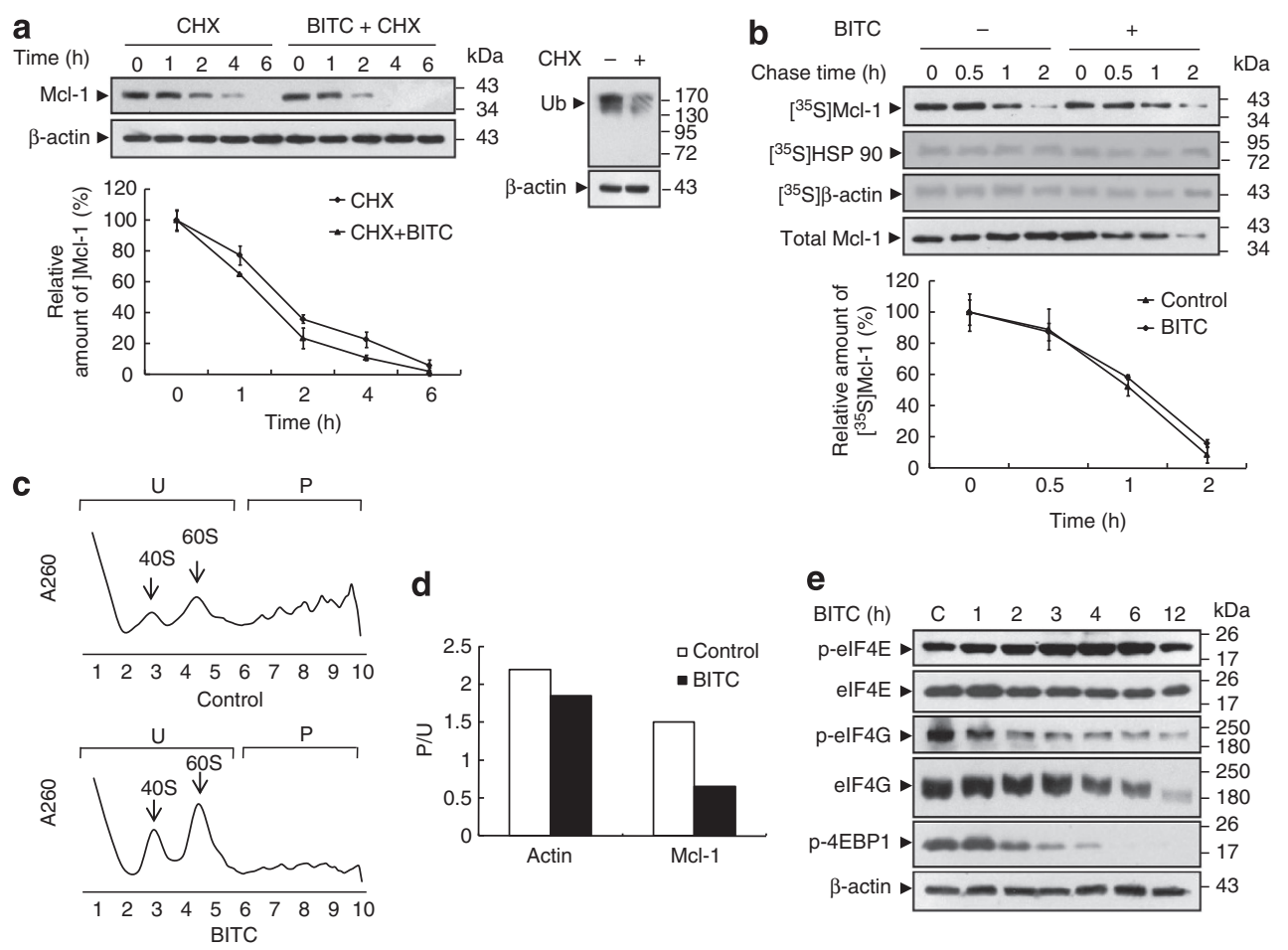

Figure 5 BITC induces Mcl-1 downregulation through inhibition of translation. (a) Jurkat cells were pretreated with $20 \mu \mathrm{M} \mathrm{CHX}$ for $1 \mathrm{~h}$, followed by treatment with or without $8 \mu \mathrm{M}$ BITC for varying intervals as indicated. After treatment, total cellular extracts were prepared and subjected to western blot assay using antibodies against Mcl-1 and $\beta$-actin. To validate the effect of $\mathrm{CHX}$, Jurkat cells were treated with or without $\mathrm{CHX}(20 \mu \mathrm{M})$ for $4 \mathrm{~h}$. After treatment, whole-cell lysates were obtained and subjected to western blot analysis using antibodies against ubiquitin $(\mathrm{Ub})$ and $\beta$-actin. (b) Jurkat cells were labeled with $\left[{ }^{35}\right.$ S]methionine as described in the Materials and Methods section and chased for the designated periods in the presence or absence of BITC. At the end of the indicated intervals, synthesis of new Mcl-1, $\beta$-actin, and heat-shock protein 90 (hsp90) proteins were measured by immunoprecipitation. The immunoprecipitates were subjected to sodium dodecyl sulfate-polyacrylamide gel electrophoresis (SDS-PAGE), followed by autoradiography. In (a) and (b), densitometric analysis of the blots were performed by the Quantity One software and plotted with respect to time. (c) Lysates from cells treated without or with $8 \mu \mathrm{M}$ BITC for $6 \mathrm{~h}$ were fractionated by sucrose gradient centrifugation. The positions of the $40 \mathrm{~S}$ and $60 \mathrm{~S}$ ribosomal subunits are indicated. U, fraction containing untranslated/initiated mRNAs; $P$, polysomal fraction. (d) Amplification of actin and Mcl-1 mRNAs in $U$ and $P$ fractions by quantitative real-time reverse transcription-polymerase chain reaction (RT-PCR). The insets represent the P/U ratio in the control (white bars) or BITC-treated (black bars) cells for each mRNA tested. (e) Jurkat cells were treated with $8 \mu \mathrm{M}$ BITC for the designated periods. After treatment, total cellular extracts were prepared and subjected to western blot analysis using antibodies against phosphorylated (p)-elF4E, elF4E, p-elF4G, elF4G, p-4EBP1, and $\beta$-actin. Each lane was loaded with $30 \mu \mathrm{g}$ of protein. Two additional studies yielded equivalent results

rapid decrease in $\mathrm{Mcl}-1$ protein levels. A critical question then arises regarding the mechanism by which Mcl-1 downregulation occurs during BITC treatment.

It has been shown that several cyclin-dependent kinase inhibitors, including flavopiridol, roscovitine, and SU9516, downregulate $\mathrm{Mcl}-1$ expression in leukemia cells through inhibition of RNA polymerase II, leading to transcriptional repression. ${ }^{27-29}$ Our data indicated that BITC failed to decrease substantially $\mathrm{Mcl}-1$ mRNA levels and promoter activity. These findings argue against the possibility that BITC downregulates $\mathrm{Mcl}-1$ protein through inhibition of transcription.

Another major mechanism by which $\mathrm{Mcl}-1$ protein level could be regulated is degradation by the proteasome system. It has been shown that the elimination of $\mathrm{Mcl}-1$ via DNA damage can be blocked by MG132, a proteasome inhibitor, suggesting a role for the ubiquitin-proteasome pathway in apoptosis. ${ }^{30}$ However, pretreatment with MG132 failed to block the downregulation of Mcl-1 mediated by BITC. Our findings argue strongly against the possibility that BITC downregulates $\mathrm{Mcl}-1$ protein through the proteasome system. It should be noted that $\mathrm{Mcl}-1$ can be the target of degradation of caspase-3. ${ }^{31}$ Caspase-mediated cleavage might contribute to the downregulation of $\mathrm{Mcl}-1$ expression as caspases can cleave $\mathrm{Mcl}-1$ following two aspartic acid residues (Asp ${ }^{127}$ and $\left.A s p^{157}\right)$. However, the findings that BITC-induced the downregulation of $\mathrm{Mcl}-1$ was not completely attenuated by caspase inhibition, raising the possibility that factors other than caspase-mediated events are involved in this phenomenon.

Having ruled out the mechanism by which BITC induced downregulation of $\mathrm{Mcl}-1$ through inhibition of transcription and the ubiquitin-proteasome pathway, the major remaining possibility is that BITC could downregulate $\mathrm{Mcl}-1$ protein levels through inhibition of translation. Indeed, our results indicate that a marked inhibition of $\mathrm{Mcl}-1$ translation was noted following exposure of cells to BITC. Notably, treatment with BITC slightly accelerated the clearance of Mcl-1 protein after inhibition of protein synthesis by $\mathrm{CHX}$. However, BITC did not enhance the elimination of pre-existing $\mathrm{Mcl}-1$ protein in cells prelabeled with $\left[{ }^{35}\right.$ S $]$ methionine, suggesting that inhibition of translation played a major role in BITC-induced downregulation of Mcl-1 protein levels. Generally, translation is primarily regulated by several initiation factors. The initiation complex elF4F, a heterotrimeric protein composed of elF4E, elF4G, 
a

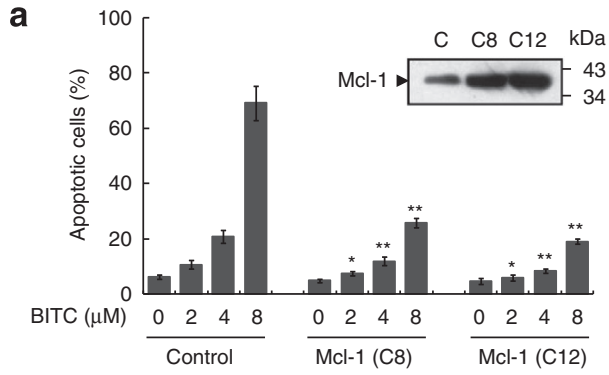

b

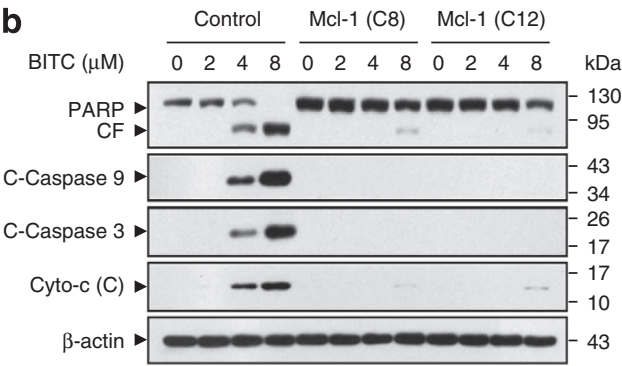

C

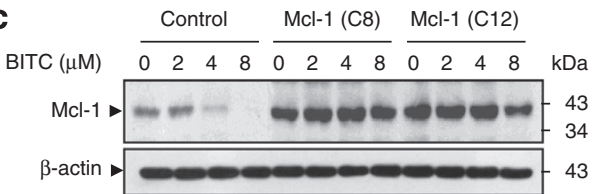

d

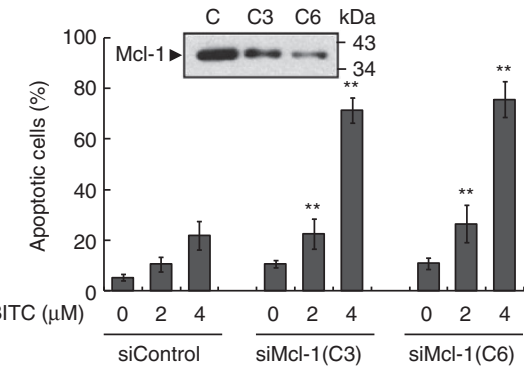

e

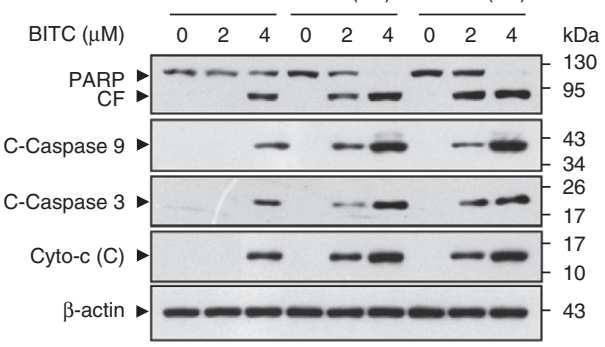

f

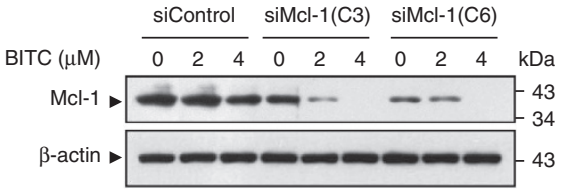

Figure 6 Enforced expression of Mcl-1 blocks BITC-mediated apoptosis, and diminished expression of Mcl-1 by siRNA enhances BITC-mediated apoptosis in Jurkat cells. (a) Total cellular extracts were prepared from an empty vector (Control) and two selected populations of cells (Mcl-1(C8) and Mcl-1(C12)) of Jurkat cells stably overexpressing $\mathrm{Mcl}-1$, and then subjected to western blot assay using antibody against Mcl-1. Mcl-1(C8), Mcl-1(C12), and empty vector control cells were treated with $0,2,4$, and $8 \mu \mathrm{M} \mathrm{BITC}$ for $12 \mathrm{~h}$. After treatment, cells were stained with Annexin V/PI, and apoptosis was determined using flow cytometry as described in the Materials and Methods section. The values obtained from Annexin V/PI assays represent the mean \pm S.D. for three separate experiments. * ${ }^{*}$ Values for Mcl-1(C8) and Mcl-1(C12) cells treated with BITC were significantly decreased compared with those for the empty vector control cells by the Student's $t$ test; $P<0.01$. (b and $\mathbf{c}$ ) After treatment as indicated in (a), total cellular and cytosolic (C) fractions were prepared and subjected to western blot assay using antibodies against PARP, cleaved-caspase (C-Caspase)-9, cleaved-caspase-3, Mcl-1, cytochrome $c$, and $\beta$-actin. (d) Jurkat cells were stably infected with lentivirus containing siRNA specific for control (siControl) or Mcl-1 (siMcl-1), and total cellular extracts were prepared and subjected to western blot assay using antibody against Mcl-1. siMcl-1(C3), siMcl-1(C6), and siControl cells were treated with BITC at the indicated concentrations for $12 \mathrm{~h}$. After treatment, cells were stained with Annexin V/PI, and apoptosis was determined using flow cytometry as described in the Materials and Methods section. The values obtained from Annexin V/PI assays represent the mean \pm S.D. for three separate experiments. ${ }^{*}$ Values for siMcl-1(C3) and siMcl-1(C6) cells treated with BITC were significantly increased compared with those for the siControl cells by the Student's $t$ test; $P<0.01$. (e and f) siMcl- 1 (C3), siMcl-1(C6), and siControl cells were treated with BITC at the indicated concentrations for $12 \mathrm{~h}$, after which total cellular and cytosolic fractions were prepared and subjected to western blot assay using antibodies against PARP, cleaved-caspase-9, cleaved-caspase-3, Mcl-1, cytochrome $c$, and $\beta$-actin

and elF4A, has a critical role in the translation of the mRNAs. The center of the elF4F complex is elF4G, a modular protein and the docking platform for several translation initiation factors and regulatory proteins, including mitogen-activated protein kinase-interacting kinases 1 and $2 .^{32}$ The elF4G family consists of three isoforms, including elF4GI, elF4GIl, and p97/DAP5/NAT1. Both elF4GI and elF4GII are involved in cap-dependent translation, and p97/DAP5/NAT1 could be a caspase-activated translation factor that can mediate its own cap-independent translation. ${ }^{33}$ The recent studies have indicated that phosphorylation of elF4G at Ser1108 has been characterized as correlating with translation. ${ }^{34}$ The anabolic agents, such as insulin, increase the phosphorylation of elF4G at Ser1108 through a mammalian target of rapamycindependent pathway. ${ }^{35}$ Insulin-like growth factor-1 induces regulation of cap-dependent translation through elF4G phosphorylation, suggesting that elF4G phosphorylation is a molecular marker associated with enhanced cap-dependent translation. ${ }^{36}$ In this context, BITC potently suppressed phosphorylation of elF4G at Ser1108 at early time point of BITC exposure, suggesting that inhibition of elF4G phosphorylation could be responsible for BITC-mediated downregulation of Mcl-1 through inhibition of cap-dependent translation. By using polysome analysis and quantitative real-time RT-PCR, our data also indicates that BITC downregulates Mcl-1 through inhibition of cap-dependent translation, further confirming that inhibition of cap-dependent translation through dephosphorylation of elF4G could contribute to BITCmediated $\mathrm{Mcl}-1$ downregulation. A clearer characterization of the functional role of elF4G dephosphorylation in the disruption of $\mathrm{Mcl}-1$ translation by BITC awaits further study.

It is significant that enforced expression of $\mathrm{Mcl}-1$ markedly diminished BITC-mediated lethality in Jurkat cells, arguing that downregulation of Mcl-1 has a critical role in BITC-related lethality. Consistent with this notion, Mcl-1 overexpression largely inhibited caspase activation and cytochrome $c$ release. These findings are consistent with previous study, which demonstrated that $\mathrm{Mcl}-1$ operates upstream of cytochrome $c$ 
a

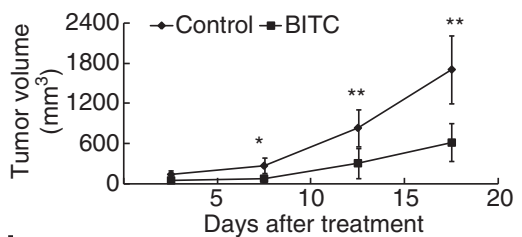

b

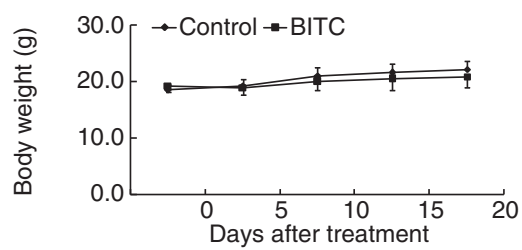

C

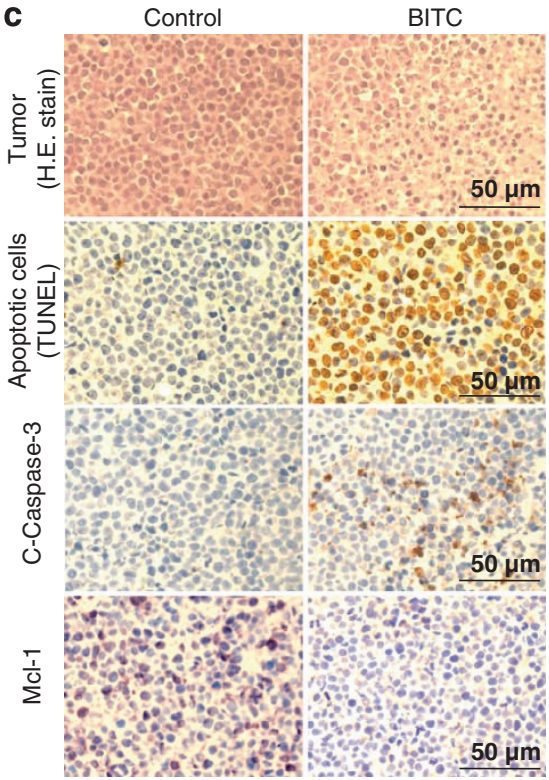

Figure 7 BITC exhibits antitumor activity and induces apoptosis in the xenograft animal model. (a) A 5-week-old nude mice inoculated subcutaneously with Jurkat cell $\left(2 \times 10^{6} / 0.2 \mathrm{ml}\right.$ per mouse). At 3 days after tumor inoculation, mice were randomized into a control group (10 mice per group) and a treated group (10 mice per group, BITC

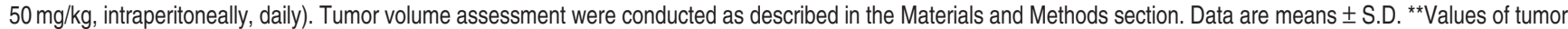
volume for BITC treatment groups were significantly decreased compared with those for the control group by Student's $t$-test; $P<0.05$. (b) Body weight of mice during the 20 days of BITC treatment. (c) Tumors were obtained from animals 20 days after drug exposure. Tumors were fixed and stained with hemtoxylin and eosin (H\&E) stain to examine tumor cell morphology, using TUNEL assay to determine apoptosis, and using immunohistochemistry to determine the levels of cleaved-caspase-3 (C-Caspase-3) and Mcl-1. The sections were lightly counterstained with 4',6-diamidino-2-phenylindole (DAPI) and photographed with a Scan Scope. Scale bar represents $50 \mu \mathrm{m}$

release and caspase activation in UV-treated HeLa cells. ${ }^{24}$ In addition, the knockdown of $\mathrm{Mcl}-1$ in Jurkat cells led to a significant increase in BITC-mediated cytochrome $c$ release, caspase activation, and apoptosis. Such findings are accordant with the studies that indicated that downregulation of $\mathrm{Mcl}-1$ through siRNA is sufficient to induce apoptosis in multiple myeloma cells. ${ }^{37}$

Previous studies have shown that BITC markedly inhibits tumor growth of human breast and pancreatic cancer cell xenografts. ${ }^{7,14}$ However, little is known about inhibitory effects of BITC on tumor growth of human leukemia xenograft model. In our studies using a nude mice Jurkat xenograft model, tumor volumes were reduced compared with controls after BITC treatment, indicating an antileukemia activity of this compound. To further validate the apoptotic mechanism found in vitro, we next examined the TUNEL staining, cleaved-caspase-3, and $\mathrm{Mcl}-1$ expression in tumor specimens obtained from control- and BITC-treated animals. The increase in TUNEL-positive cells, caspase-3 activation, and the decrease in $\mathrm{Mcl}-1$ expression were detected in the BITCtreated xenografts compared with the control group. To the best of our knowledge, this is the first report that describes an effective extrapolation of the in vitro apoptosis-inducing effects of BITC on the leukemia cells to the in vivo situation.

In conclusion, these findings indicate that BITC effectively induces apoptosis in human leukemia cell lines, primary AML blasts, and leukemia xenograft. This effect occurs in association with the downregulation of $\mathrm{Mcl}-1$ through inhibition of translation, leading, in turn, to Bax translocation and nuclear AIF accumulation, and culminating in cytochrome $c$ release and caspase activation. Dephosphorylation of elF4G could contribute to the inhibition of Mcl-1 translation mediated by BITC. This study could provide a better understanding of how BITC exerts its antileukemic activity in vivo and aid in developing this compound to treat leukemia and possibly other hematologic malignancies.

\section{Materials and Methods}

Chemicals and reagents. BITC was purchased from LKT Laboratories (St. Paul, NM, USA). Z-VAD-FMK, MG132, and CHX were from EMD Biosciences (La Jolla, CA, USA), and nocadazole was from Sigma-Aldrich (St. Louis, MO, USA). Antibodies against AIF, cytochrome $c$, cyclin A, cyclin B1, cdc-2, histone $\mathrm{H} 1$, and $\beta$-actin were purchased from Santa Cruz Biotechnology (Santa Cruz, CA, USA); Bcl-xL, XIAP, cytochrome $c$ oxidase (COX) IV, Bad, ubiquitin, elF4E, phospho-elF4E (Ser209), phospho-4E-BP1 (Thr37/46), elF4G, phospho-elF4G (Ser1108), phospho-cdc2 (Tyr15), cleaved-caspase-3, and cleaved-caspase-9 were purchased from Cell Signaling Technology (Beverly, MA, USA); Bcl-2, Mcl-1, and Bax were purchased from BD Pharmingen (San Diego, CA, USA); Mcl-1 for immunohistochemistry was purchased from Abcam (Cambridge, MA, USA); and PARP was purchased from Epitomics (Burlingame, CA, USA).

Cell culture. Jurkat, U937, and HL-60 cells were purchased from American Type Culture Collection (ATCC, Manassas, VA, USA) and cultured in RPMI 1640 medium containing $10 \%$ fetal bovine serum (FBS).

Normal human peripheral blood mononuclear cells were obtained from blood samples collected from healthy volunteers. Peripheral blood samples were obtained from eight patients with newly diagnosed AML after informed consent. Approval was obtained from the Southwest Hospital (Chongqing, China) institutional review board for these studies. AML blasts were isolated by density gradient centrifugation over Histopaque-1077 (Sigma Diagnostics, St. Louis, MO, USA) at $400 \times \mathrm{g}$ for $38 \mathrm{~min}$. Isolated mononuclear cells were washed and assayed for total number and viability using Trypan blue exclusion. Blasts were suspended at $8 \times 10^{5} / \mathrm{ml}$ and incubated in RPMl 1640 medium containing 10\% FBS in 24-well plates.

Human Mcl-1 lentiviral construct was generated by inserting human full-length Mcl-1 cDNA into Ubi-MCS-3FLAG-IRES-puromycin lentiviral vector (GeneChem, Shanghai, China). The human Mcl-1 lentiviral expression plasmid or 
GFP-puromycin-LV vector was cotransfected into 293Ta cells with the Lenti-Pac HIV Packaging Mix (GeneChem, Shanghai, China). Lentivirus-containing supernatants were harvested $48 \mathrm{~h}$ after transfection. To establish stable Mcl-1overexpressing cell lines, Jurkat cells were transduced with serial dilutions of lentiviral supernatant in the presence of $5 \mu \mathrm{g} / \mathrm{ml}$ polybrene and selected by $5 \mu \mathrm{g} / \mathrm{ml}$ puromycin. Thereafter, cells from each population of cells were analyzed for Mcl-1 expression by western blot. And two selected populations of cells, designated C8 and $\mathrm{C12}$, which displayed overexpression of Mcl-1 compared with empty vector controls (Ubi-MCS-EGFP-3FLAG-2A-Puro), were used in all experiments.

Western blotting. The total cellular samples were washed two times with ice-cold PBS and lysed in $1 \times$ NuPAGE LDS sample buffer (Invitrogen, Carlsbad, CA, USA). The protein concentration was determined using Enhanced BCA Protein Assay Reagent (Beyotime, Jiangsu, China) and $30 \mu \mathrm{g}$ of sample proteins were separated by SDS-PAGE, and transferred to PVDF membrane. Membranes were blocked with $5 \%$ fat-free dry milk in Tris-buffered saline containing $0.05 \%$ Tween-20 and incubated with antibodies. Protein bands were detected by incubating with horseradish peroxidase-conjugated antibodies (Kirkegaard and Perry Laboratories, Gaithersburg, MD, USA) and visualized with enhanced chemiluminescence reagent (Perkin-Elmer Life Sciences, Boston, MA, USA).

Apoptosis assay. Apoptotic cells were measured by staining with FITCconjugated Annexin V/propidium iodide (PI) (BD Pharmingen, San Diego, CA, USA) and determining with flow cytometer according to the manufacturer's instructions as described previously. ${ }^{38}$ Both early apoptotic (Annexin V-positive, $\mathrm{PI}$-negative) and late apoptotic (Annexin V-positive and PI-positive) cells were included in cell death determinations.

Cell cycle analysis. Cell cycle analysis was performed on the harvested cell pellets treated with $0.1 \%$ Triton $\mathrm{X}-100,3.8 \mathrm{mM} \mathrm{Na}$ citrate in $\mathrm{ddH}_{2} \mathrm{O}$, and $\mathrm{PI}$ solution $(50 \mu \mathrm{g} / \mathrm{ml})$ containing RNase B $(7 \mathrm{kU} / \mathrm{ml})$. The mixture was analyzed by a flow cytometer after $30 \mathrm{~min}$. The cell cycle distribution was measured using the FlowJo software (Treestar, Ashland, OR, USA).

Mcl-1 pulse-chase. Jurkat cells were plated at a density of $5 \times 10^{6}$ cells, in methionine-free RPMl for $30 \mathrm{~min}$, and then labeled with $100 \mu \mathrm{Ci} / \mathrm{ml}\left[{ }^{35} \mathrm{~S}\right]$ methionine (ICN; Biomedicals Inc., Irvine, CA, USA) for $60 \mathrm{~min}$ at $37^{\circ} \mathrm{C}$. Cells were then washed in PBS and cultured in complete RPMI containing fetal bovine serum and excess of cold methionine $(10 \mathrm{mM})$ and cysteine $(5 \mathrm{mM})$ for the indicated periods in the presence or absence of $8 \mu \mathrm{M} \mathrm{BITC}$. At the end of the indicated intervals, cells were collected and subsequently subjected to immunoprecipitation using Mcl-1 antibody as described above. The immunoprecipitates were subjected to SDS-PAGE followed by autoradiography.

RNA interference. Oligonucleotides with the following targeting sequences were used for the cloning of small hairpin RNA-encoding sequences in hU6-MCSubiquitin-EGFP-IRES-puromycin lentiviral RNAi vector: Mcl-1, 5'-GCTAAACACTT GAAGACCATA-3' . After cotransfection of lentiviral packaging plasmids into 293Ta cells, lentivirus-containing supernatants were harvested $48 \mathrm{~h}$ after transfection. Jurkat cells were infected with the lentiviral supernatant plus $5 \mu \mathrm{g} / \mathrm{ml}$ polybrene and selected by $5 \mu \mathrm{g} / \mathrm{ml}$ puromycin. Thereafter, cells from each clone were analyzed for Mcl-1 expression by western blot. And two selected populations of cells, designated $\mathrm{C} 3$ and $\mathrm{C} 6$, were used in all experiments.

Confocal immunofluorescence microscopy. At the end of each incubation, cells were fixed with $4 \%$ paraformaldehyde at room temperature for $30 \mathrm{~min}$, permeabilized by $0.1 \%$ Triton X-100 in PBS at room temperature for $15 \mathrm{~min}$, and then blocked nonspecific binding with $3 \%$ bovine serum albumin in PBS for $30 \mathrm{~min}$ at room temperature. Cells were further incubated with primary polyclonal anti-AIF antibody at $4{ }^{\circ} \mathrm{C}$ overnight, followed by secondary antibody (Alexa Fluor 647 donkey anti-rabbit IgG; Invitrogen) for $1 \mathrm{~h}$. After washing, the nuclei were counterstained with $0.1 \mu \mathrm{g} / \mathrm{ml}$ DAPI (Sigma-Aldrich Co., St. Louis, MO, USA) for $10 \mathrm{~min}$, and then sealed in antifade reagent (Beyotime, Jiangsu, China). Confocal micrographs were scanned by a laser confocal scanning microscope TCS SP5; Leica Microsystems, Mannhein, Germany.

Analysis of nuclear AIF, cytosolic cytochrome $c$, and Bax and mitochondrial Bax. For nuclear fractionations, cells $\left(2 \times 10^{6}\right)$ were fractionated by Nuclear and Cytoplasmic Protein Extraction Kit (Beyotime) according to the manufacturer's instructions. Mitochondrial and cytosolic fractions were obtained as described previously. ${ }^{27}$ These fractions were prepared and subjected to western blot assay to monitor expression of AIF, cytochrome $c$, and Bax.

Polysome analysis. Sucrose gradient centrifugation was used to separate ribosomes into polysomal and subpolysomal forms. After centrifugation, gradients were collected into 10 fractions, while UV absorbance was recorded at $260 \mathrm{~nm}$. The fractions corresponding to subpolysomes and polysomes were pooled. The RNA in the pooled fractions was extracted and analyzed by quantitative real-time RT-PCR.

Quantitative real-time RT-PCR. Total RNA and pooled sucrose gradient fractionated RNA were extracted using the RNeasy mini kit (Qiagen, Valencia, CA, USA). Quantitative real-time PCR analysis was carried out on an iCycler (Bio-Rad Laboratories, Munchen, Germany) using the RealMasterMix (SYBR Green) (Tiangen Biotech, Beijing, China) according to the manufacturer's instructions. mRNA levels were normalized to $\beta$-actin level. Primers used for amplification of $\mathrm{Mcl}-1$ and $\beta$-actin were purchased from Invitrogen. Sequences were as follows: $\beta$-actin - $5^{\prime}$-GGACTTCGAGCAAGAGATGG-3' (forward), $5^{\prime}$-AGCACTGTGTTGG CGTACAG-3' (reverse); Mcl-1 - 5'-TAAGGACAAAACGGGACTGG-3' (forward), $5^{\prime}$-ACCAGCTCCTACTCCAGCAA-3' (reverse).

Reporter gene assay. Jurkat cells were cotransfected with a $-203 /+$ 10-Mcl-1-pGL2 plasmid (kindly provided by Dr. PK Burnette, Moffitt Research Center, Tampa, FL, USA), in which firefly luciferase is driven by the -203 to +10 element of the Mcl-1 gene promoter, or the pGL2-basic empty vector (Promega, Madison, WI, USA) and pRL-TK-luc plasmid encoding for Renilla luciferase. Cells were incubated for $12 \mathrm{~h}$ and then treated with BITC for an additional $12 \mathrm{~h}$, after which the activity of firefly and Renilla luciferases was measured using the DualLuciferase reporter assay system (Promega). Values for firefly luciferase activity were normalized to those obtained for Renilla luciferase activity.

Xenograft model and immunohistochemical evaluation. Nude mice (5 weeks old) were purchased from Vital River Laboratories (Beijing, China). Animal experiments were approved by the Institutional Animal Care and Use Committee (IACUC) of the university. Jurkat cells $\left(2 \times 10^{6} / 0.2 \mathrm{ml}\right.$ per mouse) were suspended in sterile PBS and injected subcutaneously into the right flank of the mice. Mice were randomly assigned in two groups of 10 mice per group. At 3 days after tumor inoculation, the treatment group received BITC $(50 \mathrm{mg} / \mathrm{kg}$, intraperitoneally for 20 days). The control group received an equal volume of solvent control. Tumor size and body weight were measured every 5 days. Tumor volumes were determined by a caliper and calculated according to the formula (width ${ }^{2} \times$ length)/2. All animals were killed immediately after 20 days of drug exposure.

TUNEL assay. Apoptosis in tumor tissue sections was determined using In Situ Cell Death Detection kit (Roche, Mannheim, Germany). Briefly, tumor tissue sections of formalin-fixed, paraffin-embedded specimens were dewaxed in xylene and rehydrated in a graded series of ethanol. The tumor samples were incubated with proteinase $\mathrm{K}(2 \mathrm{mg} / \mathrm{ml})$, and the TUNEL staining was performed according to the manufacturer's instructions.

Statistical analysis. Densitometric analysis was performed using the Quantity One software (Bio-Rad) to determine the relative abundance of protein expression. The values were presented as means \pm S.D. for at least three independent experiments. Student's $t$-test were used for statistical analysis. $P<0.05\left(^{*}\right)$ or $\left.P<0.01{ }^{* *}\right)$ was considered significantly different.

\section{Conflict of Interest}

The authors declare no conflict of interest.

Acknowledgements. This work was supported by the National Natural Science Foundation of China, No. 30971288 (N.G.) and No. 30972468 (B.C.), Chongqing Natural Science Foundation, China, No. $2008 B B 5290$ (B.C.).

1. Hecht SS. Inhibition of carcinogenesis by isothiocyanates. Drug Metab Rev2000; 32: 395-411.

2. Conaway CC, Yang YM, Chung FL. Isothiocyanates as cancer chemopreventive agents: their biological activities and metabolism in rodents and humans. Curr Drug Metab 2002; 3 233-255. 
3. Witschi $\mathrm{H}$, Uyeminami D, Moran D, Espiritu I. Chemoprevention of tobacco-smoke lung carcinogenesis in mice after cessation of smoke exposure. Carcinogenesis 2000; 21 977-982.

4. Sugie S, Okumura A, Tanaka T, Mori H. Inhibitory effects of benzyl isothiocyanate and benzyl thiocyanate on diethylnitrosamine-induced hepatocarcinogenesis in rats. Jpn $J$ Cancer Res 1993; 84: 865-870.

5. Yang YM, Conaway CC, Chiao JW, Wang CX, Amin S, Whysner J et al. Inhibition of benzo(a)pyrene-induced lung tumorigenesis in $\mathrm{A} / \mathrm{J}$ mice by dietary $\mathrm{N}$-acetylcysteine conjugates of benzyl and phenethyl isothiocyanates during the postinitiation phase is associated with activation of mitogen-activated protein kinases and p53 activity and induction of apoptosis. Cancer Res 2002; 62: 2-7.

6. Warin R, Chambers WH, Potter DM, Singh SV. Prevention of mammary carcinogenesis in MMTV-neu mice by cruciferous vegetable constituent benzyl isothiocyanate. Cancer Res 2009; 15: 9473-9480.

7. Warin R, Xiao D, Arlotti JA, Bommareddy A, Singh SV. Inhibition of human breast cancer xenograft growth by cruciferous vegetable constituent benzyl isothiocyanate. $\mathrm{Mol}$ Carcinogen 2010; 49: 500-507.

8. Lamy E, Scholtes C, Herz C, Mersch-Sundermann V. Pharmacokinetics and pharmacodynamics of isothiocyanates. Drug Metab Rev 2011; 43: 387-407.

9. Miyoshi N, Uchida K, Osawa T, Nakamura Y. A link between benzyl isothiocyanateinduced cell cycle arrest and apoptosis: involvement of mitogen-activated protein kinases in the Bcl-2 phosphorylation. Cancer Res 2004; 64: 2134-2142.

10. Kim SH, Singh SV. P53-independent apoptosis by benzyl isothiocyanate in human breast cancer cells is mediated by suppression of XIAP expression. Cancer Prev Res (Phila) 2010; 3: 718-726

11. Xiao D, Vogel V, Singh SV. Benzyl isothiocyanate-induced apoptosis in human breast cancer cells is initiated by reactive oxygen species and regulated by Bax and Bak. Mol Cancer Ther 2006; 5: 2931-2945.

12. Sahu RP, Zhang R, Batra S, Shi Y, Srivastava SK. Benzyl isothiocyanate-mediated generation of reactive oxygen species causes cell cycle arrest and induces apoptosis via activation of MAPK in human pancreatic cancer cells. Carcinogenesis 2009; 30: 1744-1753.

13. Sahu RP, Srivastava SK. The role of STAT-3 in the induction of apoptosis in pancreatic cancer cells by benzyl isothiocyanate. J Natl Cancer Inst 2009; 101: 176-193.

14. Boreddy SR, Pramanik KC, Srivastava SK. Pancreatic tumor suppression by benzyl isothiocyanate is associated with inhibition of PI3K/AKT/FOXO pathway. Clin Cancer Res 2011; 17: 1784-1795.

15. Srivastava SK, Singh SV. Cell cycle arrest, apoptosis induction and inhibition of nuclear factor kappa B activation in anti-proliferative activity of benzyl isothiocyanate against human pancreatic cancer cells. Carcinogenesis 2004; 25: 1701-1709.

16. Aichberger KJ, Mayerhofer M, Krauth MT, Skvara H, Florian S, Sonneck K et al. Identification of mcl-1 as a BCR/ABL-dependent target in chronic myeloid leukemia (CML): evidence for cooperative antileukemic effects of imatinib and mcl-1 antisense oligonucleotides. Blood 2005; 105: 3303-3311.

17. Kaufmann SH, Karp JE, Svingen PA, Krajewski S, Burke PJ, Gore SD et al. Elevated expression of the apoptotic regulator Mcl-1 at the time of leukemic relapse. Blood 1998; 91 : 991-1000

18. Hussain SR, Cheney CM, Johnson AJ, Lin TS, Grever MR, Caligiuri MA et al. Mcl-1 is a relevant therapeutic target in acute and chronic lymphoid malignancies: down-regulation enhances rituximab-mediated apoptosis and complement-dependent cytotoxicity. Clin Cancer Res 2007; 13: 2144-2150.

19. Zhou P, Qian L, Bieszczad CK, Noelle R, Binder M, Levy NB et al. Mcl-1 in transgenic mice promotes survival in a spectrum of hematopoietic cell types and immortalization in the myeloid lineage. Blood 1998; 92: 3226-3239.

20. Moulding DA, Giles RV, Spiller DG, White MR, Tidd DM, Edwards SW. Apoptosis is rapidly triggered by antisense depletion of MCL-1 in differentiating U937 cells. Blood 2000; 96: $1756-1763$.
21. Opferman JT, Iwasaki $\mathrm{H}$, Ong CC, Suh $\mathrm{H}$, Mizuno S, Akashi K et al. Obligate role of antiapoptotic MCL-1 in the survival of hematopoietic stem cells. Science 2005; 307: 1101-1104.

22. Opferman JT, Letai A, Beard C, Sorcinelli MD, Ong CC, Korsmeyer SJ. Development and maintenance of B and T lymphocytes requires antiapoptotic MCL-1. Nature 2003; 426: 671-676.

23. Song L, Coppola D, Livingston S, Cress D, Haura EB. Mcl-1 regulates survival and sensitivity to diverse apoptotic stimuli in human non-small cell lung cancer cells. Cancer Biol Ther 2005; 4: 267-276.

24. Nijhawan D, Fang M, Traer E, Zhong Q, Gao W, Du F et al. Elimination of Mcl-1 is required for the initiation of apoptosis following ultraviolet irradiation. Genes Dev 2003; 17: 1475-1486.

25. Rahmani M, Davis EM, Bauer C, Dent P, Grant S. Apoptosis induced by the kinase inhibitor BAY 43-9006 in human leukemia cells involves down-regulation of Mcl-1 through inhibition of translation. J Biol Chem 2005; 280: 35217-35227.

26. Maurer U, Charvet C, Wagman AS, Dejardin E, Green DR. Glycogen synthase kinase-3 regulates mitochondrial outer membrane permeabilization and apoptosis by destabilization of MCL-1. Mol Cell 2006; 21: 749-760.

27. Gao N, Kramer L, Rahmani M, Dent P, Grant S. The three-substituted indolinone cyclindependent kinase 2 inhibitor 3-[1-(3H-imidazol-4-yl)-meth-(Z)-ylidene]-5-methoxy-1, 3-dihydro-indol-2-one (SU9516) kills human leukemia cells via down-regulation of Mcl-1 through a transcriptional mechanism. Mol Pharmacol 2006; 70: 645-655.

28. Chen R, Keating MJ, Gandhi V, Plunkett W. Transcription inhibition by flavopiridol: mechanism of chronic lymphocytic leukemia cell death. Blood 2005; 106: 2513-2519.

29. MacCallum DE, Melville J, Frame S, Watt K, Anderson S, Gianella-Borradori A et al. Seliciclib (CYC202, R-Roscovitine) induces cell death in multiple myeloma cells by inhibition of RNA polymerase II-dependent transcription and down-regulation of Mcl-1. Cancer Res 2005; 65: 5399-5407.

30. Zhong Q, Gao W, Du F, Wang X. Mule/ARF-BP1, a BH3-only E3 ubiquitin ligase, catalyzes the polyubiquitination of $\mathrm{Mcl}-1$ and regulates apoptosis. Cell 2005; 121 : 1085-1095.

31. Weng C, Li Y, Xu D, Shi Y, Tang H. Specific cleavage of Mcl-1 by caspase-3 in tumor necrosis factor-related apoptosis-inducing ligand (TRAIL)-induced apoptosis in Jurkat leukemia T cells. J Biol Chem 2005; 280: 10491-10500.

32. Prevot $D$, Darlix JL, Ohlmann T. Conducting the initiation of protein synthesis: the role of elF4G. Biol Cell 2003; 95: 141-156.

33. Holcik M, Sonenberg N. Translational control in stress and apoptosis. Nat Rev Mol Cell Biol 2005; 6: 318-327.

34. Vary TC, Lynch CJ. Nutrient signaling components controlling protein synthesis in striated muscle. J Nutr 2007; 137: 1835-1843.

35. Harris TE, Chi A, Shabanowitz J, Hunt DF, Rhoads RE, Lawrence Jr JC. mTORdependent stimulation of the association of elF4G and elF3 by insulin. EMBO J 2006; 25: 1659-1668.

36. Quevedo C, Salinas M, Alcazar A. Regulation of cap-dependent translation by insulin-like growth factor-1 in neuronal cells. Biochem Biophys Res Commun 2002; 291: 560-566.

37. Zhang B, Gojo I, Fenton RG. Myeloid cell factor-1 is a critical survival factor for multiple myeloma. Blood 2002; 99: 1885-1893.

38. Gao N, Budhraja A, Cheng S, Yao H, Zhang Z, Shi X. Induction of apoptosis in human leukemia cells by grape seed extract occurs via activation of c-Jun NH2-terminal kinase. Clin Cancer Res 2009; 15: 140-149.

(c) (i) $(\Theta$ Cell Death and Disease is an open-access journal chy ${ }_{\mathrm{BY}} \mathrm{NC}$ published by Nature Publishing Group. This work is licensed under the Creative Commons Attribution-NonCommercial-No Derivative Works 3.0 Unported License. To view a copy of this license, visit http://creativecommons.org/licenses/by-nc-nd/3.0/ 